\title{
MODELO URBANO Y LITORAL: UNA ASIGNATURA PENDIENTE
}

\author{
Raquel Rodríguez Alonso (Arquitecta - Profesora asociada DUyOT)
}

Como sistema vivo y en constante equilibrio, el litoral se va acomodando a los embates del mar y dicho proceso permite la salvaguarda de los usos y actividades antrópicas y de los ecosistemas situados tierra adentro. Como fuente de recursos naturales y económicos, la explotación, ocupación y transformación del litoral ha sido muy intensa en España desde los años 60, y uno de los objetivos clave del reciente boom inmobiliario.

El valor ambiental del litoral se recoge por primera vez en el marco jurídico durante los años 1980. La nueva estructura trata de poner solución a los problemas heredados: a través de herramientas de protección que salvaguarden el territorio de nuevas presiones; poniendo fecha de caducidad a construcciones y actividades inadecuadas; ampliando el conocimiento sobre la forma de funcionamiento del sistema físico; o interviniendo en la regeneración de los tramos de costa más afectados, normalmente urbanos. La coyuntura económica y social derivada de la crisis del petróleo ayudará a avanzar en la visión compleja del territorio, pero también pesará en las decisiones sobre el modelo económico y el reparto de inversiones. El marco legal funcionará no como una bisagra entre el medio físico y los intereses lucrativos sino como un muro de contención que pretende frenar la deriva ambiental pero también económica. Así, el litoral heredado por el reciente boom inmobiliario se caracteriza por un marco legal y jurídico donde se acumulan las restricciones en el papel y los agentes en la gestión del territorio se han multiplicado; un sistema físico en el que las numerosas actuaciones públicas han estado destinadas a salvaguardar los intereses económicos pero no han sido suficientes para paralizar su degradación ni las nuevas amenazas y riesgos; y un modelo económico donde el único destino posible para el litoral es la coalición turismo-producción inmobiliaria.

El boom inmobiliario se traduce en un importante incremento de la presión sobre un espacio altamente antropizado y ambientalmente degradado. La demanda sobre los recursos litorales parte desde todas las políticas sectoriales sin que el marco legal sobre costas pueda detener muchos de los procesos. Las políticas de protección del territorio desarrolladas durante la década anterior ponen freno en parte a este crecimiento, pero no son suficientes ni homogéneas en el territorio. Además, entra en carga el complejo sistema administrativo y competencial, y la STC de 1991 sienta un precedente fundamental en la gestión de la costa. Dentro del ámbito regulado por la Ley de 1988, la Administración General del Estado gestionará el Dominio Público Marítimo Terrestre, mientras que todas las decisiones a tomar en el área de propiedad privada, servidumbres de tránsito y protección y zona de influencia, quedan reguladas por las determinaciones derivadas de las políticas urbanísticas y de ordenación del territorio. La STC de 1997, que anula gran parte de la Ley de Suelo de 1992, reducirá aún más la posibilidad de una visión conjunta sobre el litoral, enfrentando formas de hacer en un espacio continuo. Las decisiones sobre el modelo urbanístico y territorial, origen de la mayoría de las presiones sobre el medio físico, se independizan del 
equilibrio ambiental de la costa. La mayoría del planeamiento urbanístico de los municipios litorales revisa el modelo anterior con incrementos desmedidos en la clasificación del suelo y en el número de nuevas viviendas. A esta situación hay que sumar las consecuencias del estallido de la burbuja, con miles de viviendas construidas y sin vender, una importante superficie de solares sin edificar, y promociones inmobiliarias paralizadas a mitad del proceso de urbanización o construcción.

Las consecuencias visibles de la crisis son todavía mayores que a finales de los años 1970: por el volumen del crecimiento inmobiliario, por la acumulación de presiones y problemas sobre el sistema físico y por el sobredimensionamiento de la demanda estimada que afectó tanto a los productos inmobiliarios como a las infraestructuras: incremento en los kilómetros de autovías y autopistas; nuevos aeropuertos construidos y sin uso como en el caso de Castellón o Murcia; y expansión de todas las instalaciones portuarias, destacando el aumento del número de atraques deportivos y la ampliación exterior de los puertos de interés general sobre nuevos tramos de costa, con el agravante de que el vínculo entre interés general, desarrollo económico y sistema portuario hace que las afecciones que su actividad provoca en el entorno se entiendan como un mal asumible. El estallido de la burbuja inmobiliaria en 2007 paraliza el desarrollo de muchas de esas propuestas, pero no las cancela. Así, el litoral a gestionar en el futuro parte de un marco jurídico en el que la protección del litoral se ha reducido, un modelo urbano y territorial que ha consolidado físicamente o jurídicamente un desarrollo residencial e infraestructural diseñado para una demanda que no existe, y un sistema físico cada vez más degradado y amenazado por el cambio climático.

Mientras desde la política urbanística y territorial se aumentaba sin control la presión sobre el litoral, el papel de la Dirección General de Costas quedaba reducido a plantear nuevos proyectos y alternativas en las que se procurara mantener la estabilidad del frente costero y, por tanto, la defensa física de los intereses ubicados tierra adentro, dedicando así una importante parte del presupuesto público a garantizar la seguridad material y futura de los intereses económicos. Además, los riesgos inherentes al funcionamiento del sistema litoral, como la erosión costera, los temporales, las inundaciones por lluvias torrenciales o la inestabilidad de los acantilados, provocan todos los años nuevas inversiones públicas que, con carácter de urgencia, van destinadas a reconstruir lo que la inercia del sistema se ha llevado por delante.

La descoordinación entre las distintas administraciones reabre la polémica social sobre la forma de actuar en la costa, llegando en muchas ocasiones a situaciones paradigmáticas. El programa estatal de adquisición de fincas rústicas para su incorporación al Dominio Público Marítimo Terrestre tiene mucho que ver con la desconfianza entre los distintos niveles de la administración. A pesar de los esfuerzos que la comunidad científica y los poderes públicos están realizando para la evaluación de los efectos del cambio climático en la costa, en muchos casos los resultados llevan a un callejón sin salida: ya sea por la búsqueda de yacimientos de áridos para procurar la estabilidad de las playas, o por el impacto sobre las actividades económicas, el desarrollo urbano y los ecosistemas. Entre 2006 y 2008 la Dirección General de Costas redactó la Estrategia de Sostenibilidad de la Costa y el Mar, segundo intento de hacer un documento para la gestión completa del litoral español. Entre 2004 y 2008, se 
remata la revisión de los deslindes, no sin polémica, y los criterios de intervención pública en la costa se modifican parcialmente a partir de 2006, incrementando las inversiones en la regeneración y accesibilidad de áreas vírgenes, en la recuperación del patrimonio etnográfico y cultural, y condicionando las intervenciones en áreas urbanas a la liberación de los frentes situados en servidumbre de tránsito y protección. La vuelta de tuerca en la política de costas y la llegada inminente de la fecha de caducidad de las concesiones (2018) generarán bastante inquietud en los sectores económicos y en la población. La regulación de la Ley de 1988 y su aplicación se ponen en tela de juicio, y el conflicto entre los intereses privados y el valor ambiental del litoral se vuelve a hacer evidente.

A día de hoy, se puede afirmar con rotundidad que las respuestas a la pugna entre la inestabilidad del sistema litoral y la persistencia de los intereses económicos y sociales no han sido todo lo eficaces que se podría esperar. La ilusión de que las innovaciones técnicas son capaces de dar solución a los problemas y riesgos no ha dejado nunca de estar presente en la transformación del litoral. La primera reacción siempre es un nuevo intento de dominar el territorio. En el mejor de los casos, la respuesta ha sido la búsqueda de soluciones intermedias, que parten de la comprensión total o parcial de los procesos naturales, y cuyo objetivo es mantener la rentabilidad económica o social de los usos y actividades existentes, aunque muchos de ellos estén en el origen de lo que se pretende solucionar. La superposición de nuevas obras de defensa no ha conseguido parar la inercia del sistema. Como nuevos parches a los problemas, evitaban además la confrontación de los riesgos y amenazas que permanecían sobre la mesa. En el peor de los casos, la solución ha pasado por negar lo evidente, como en el caso de la reciente reforma de la Ley de Costas: se podrán relajar las reglas de actuación, reconocer todos los derechos que demandan los propietarios airados, eliminar todas las restricciones existentes, pero no se puede detener el mar.

Las consecuencias del cambio climático sobre el litoral, con incrementos de los fenómenos climáticos extremos, la subida del nivel del mar, o los cambios en la orientación local del oleaje, incorporan nuevas incógnitas al futuro de un espacio ya de por sí complejo. La desaparición de ecosistemas y hábitats que contribuyen a la regulación de los procesos costeros, a la defensa de los usos y actividades situados tierra adentro, y al mantenimiento de la vitalidad económica del litoral puede poner en tela de juicio la propia construcción social del litoral. La visión compleja e integral de los procesos económicos, sociales, jurídicos y ambientales que se superponen en la costa, reivindicada desde la década de los 1980, ha dejado de ser, si alguna vez lo fue, una alternativa dentro de las distintas formas de gestión posibles. La respuesta al futuro del litoral pasa necesariamente por la coordinación real y efectiva de todas las políticas disponibles para la gestión del territorio, pero también de todos los agentes y los intereses implicados. Sea cual sea el problema a solucionar, la toma de decisiones pasa siempre por actuar sobre los procesos litorales con el fin de permitir la continuidad de la actividad afectada, o bien, eliminar la actividad permitiendo el desarrollo de los procesos del sistema físico litoral.

En este sentido y a pesar del reparto competencial, las actuaciones en la costa y la política urbanística están condenadas a coordinarse y entenderse; partiendo de un modelo pactado, las herramientas urbanísticas pueden proporcionar una solución definitiva y más barata para la protección de los suelos situados en primera línea, 
incluso para la reubicación a corto, medio o largo plazo de los usos afectados por la subida del nivel del mar. Las tres estrategias básicas planteadas por la Agencia Europea del Medio Ambiente para procurar la adaptación de las poblaciones y áreas urbanas al cambio climático, proteger, adaptar y retirar ${ }^{68}$, pasarán necesariamente por la utilización de las herramientas de ordenación en la futura gestión del litoral.

Otro de los grandes retos será la revisión del modelo urbano heredado, adecuándolo a las necesidades reales de la población y a la capacidad de carga del propio sistema físico, entendido en su sentido amplio: la autorización del nuevo trasvase desde el Tajo al Segura y las protestas que se han generado entre los municipios situados en la cabecera ${ }^{69}$ vuelven a abrir la polémica pública sobre la gestión de un bien escaso en la confrontación entre el desarrollo económico y la protección ecológica. El litoral no puede subsistir a costa de la destrucción de parte de su sistema físico, sean cuales sean los derechos adquiridos sobre el papel.

68 Proteger o reducir el riesgo disminuyendo la probabilidad de que ocurra el suceso; Adaptar, o aumentar la capacidad de la sociedad para hacer frente a los efectos del suceso, y Retirar o reducir el riesgo limitando el potencial del suceso,

69 http://politica.elpais.com/politica/2015/08/28/actualidad/1440752893_805663.html 